\title{
Factors Determining Entrepreneurial Intentions: A Case Study from Albania
}

\author{
Genc Alimehmeti, Ph.D. \\ Department of Management, University of Tirana; E. genc.alimehmeti@unibo.it
}

Gentjan Shaqiri, Ph.D.

Department of Management, University of Tirana; E. gshaqiri@otmail.com

Doi:10.5901/ajis.2015.v4n3p233

\section{Abstract}

\begin{abstract}
This paper attempts to explain the formation of entrepreneurial intention of Albanian students by using the Theory of Planned Behavior. It aims in understanding how the personal and contextual variables, affect the entrepreneurial intention of students in Albania. The main purpose of our study is to describe, predict and analyse an important factor of the entrepreneurial process: the entrepreneurial intention. We conduct a detailed analysis of theoretical background in order to highlight a conceptual framework of entrepreneurial intention based on the model of Shapero and Sokol (1982) taken over by Krueger (1993). We draw our model on a sample of 556 students in three public universities. We use structural equation models to test our hypothesis on the entrepreneurial intention of students. The use of structural equations, aims in creating robust latent variables out of single survey questions, by assuring the reliability of the constructs. The data were tested for multi-trait with a multimethod model. Some of our findings were consistent with the theory of Planned Behavior, while others were not. The data show a positive relationship between both attitude and subjective norms with students' entrepreneurial intentions, while, as unexpected, the self-efficacy despite their positive relationship, have a lower effect over entrepreneurial intentions.
\end{abstract}

Keywords: entrepreneurial intentions; theory of planned behavior; attitude; self-efficacy; structural equations models.

\section{Introduction}

During the last couple of years, Albania has shown an increased interest in developing entrepreneurship in young ages. Empirical studies around the world suggest that more and more people are choosing self-employment and this phenomenon is found more often in young ages. While data on self-employment in Albania are scarce, there is a gap of empirical studies on entrepeneurship effects and the factors which determine the level of entrepreneurial activities.

This study investigates and seeks to understand entrepreneurship level and goals as well as the factor that impact the entrepreneurship intention of the Albanian students. The main aim is to explore students attitude towards entrepreneurship and the role that different factors have on entrepreneurial intentions. This paper studies the role of each of the determinants of entrepreneurship intention, by investigating the impact of individual characteristics and know how; personal attitude and desirability to create a business; feasibility and desirability; while controlling for external determinants such as the support of relatives and society as a whole in strengthening the entrepreneurial intentions. In addition it identifies the role of self-confidence and self-effectiveness of the Albanian students in determining their entrepreneurial intention.

The main model is based on the Theory of Planned Behavior (TPB) model as revised by Krueger et al. (2000). TPB is an extension of the Theory of Reasoned Action Ajzen (1991) by Fishbein and Ajzen (1975), to include perceived behavioral controls an additional factor. According to Ajzen (1991), TPB is suitable to explain any behavior, which requires planning, such as entrepreneurship. The main standpoint of TPB is the identification of intention as a precursor of behavior. There are three main antecedents of intention which captures the motivational factors that influence a given behavior: (1) attitude toward the behavior; (2) subjective norms; and, (3) perceived behavioral control (Ajzen, 1991). The TPB probably can be applied to any behavior that requires certain amount of planning. The model has been consistently proved robust in predicting behavior and intentions in various fields of research, such as health care (weight loss, quitting smoking), safety (seat belt usage), marketing (coupon usage) (Ajzen, 1987; Sheppard et al. 1988), and career choice (Kolvereid, 1996).

The use of the TPB in entrepreneurship studies is attracting many scholars (Autio et al., 2001; Krueger et al., 2000; Tkachev and Kolvereid, 1999). Many empirical studies on entrepreneurship have confirmed the relationship between the 
three attitudinal antecedents and entrepreneurial intentions (Kolvereid, 1996; Krueger et al., 2000). However, the empirical findings regarding the direct relationship between subjective norm and entrepreneurial intention are relatively inconsistent. Scholars have found subjective norm to significantly explain entrepreneurial intention, while others found subjective norm to be insignificant (Kolvereid, 1996; Kolvereid and Isaksen, 2006). Similar results were obtained by Tkachev and Kolvereid (1999) who surveyed 512 Russian university students and examined their entrepreneurial intentions. The authors found that the three antecedents of behaviour significantly influence the students' entrepreneurial intention.

Several studies on entrepreneurship intentions have highlighted the relationship between the three attitudinal antecedents and entrepreneurial intentions (Kolvereid, 1996; Krueger et al., 2000). Although based on the TPB, subjective norm has a direct impact on entrepreneurial intention (Ajzen, 1991; 2005), more empirical evidences on the effect of subjective norm on entrepreneurial intention are required (Krueger et al., 2000). Thus, more empirical studies have been called for confirming the TPB in entrepreneurship research field (Kolvereid, 1996; Krueger et al., 2000). Accordingly, we propose the following hypothesis in order to verify the TPB model in the context of Albanian public university students of Tirana (see Figure 1):

H1: Attitude toward entrepreneurship has a positive effect on entrepreneurial intention of students

H2: Subjective norm regarding entrepreneurship has a positive effect on the entrepreneurial intention of students. H3: Self-efficacy regarding entrepreneurship has a positive effect on the entrepreneurial intention of students.

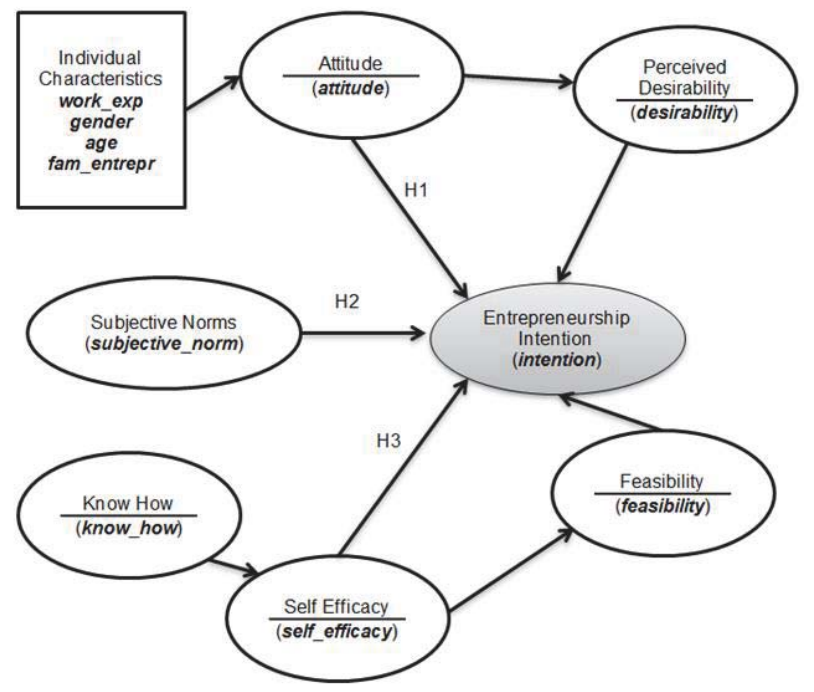

Figure 1: Model Setup and Hypothesis

\section{Methodology}

\subsection{Sample selection}

Prior research on entrepreneurship intention is focused on business and engineering students (Johnson and Craig, 2006; Kirzner, 1997, Krueger et al., 2000). Business students perceive that they are more market-oriented to sense business opportunities and that they even have abilities to generate the opportunities given their professional business training that enhances their confidence to act entrepreneurially. On the other hand, engineering students are less confident intheir capability to respond or produce entrepreneurial opportunities (Johnson and Craig, 2006).

These considerations led us to selected three Public Universities from the social, exact and agricultural sciences: University of Tirana (UT) - Faculty of Economy, Polytechnical Universityof Tirana (PU) - EletricalEngeeniring Faculty and the Agricultural University of Tirana (AU) - Faculty of Economy. Research has shown that students of the third year of the bachelor program and the first or second your of the master studies, represent a proper sample of the knowledgably 
student, well acquainted in their field of studies. Thus, we distributed hard copies of the questionnaire to all the students groups of Business Administration and Finance (UT); Electrical Engineering (PU) and Finance (AU). We distributed a hard copy of the questionnaire before lectures to over 610 students and got back 556 completed questionnaires. The sample composes a good number of representation of the total population of 1.730 students enrolled in these courses. The sample selection procedure is explained in Table 1.

Table 1: Sample selection

\begin{tabular}{|c|c|c|c|c|}
\hline & & Population & Distributed & Responses \\
\hline 1. University & Tirana & & & \\
\hline 1.a. Faculty of & conomy & & & \\
\hline Bachelor & Business Administration & 390 & 135 & 135 \\
\hline & Finance & 400 & 139 & 128 \\
\hline & Economics & 90 & 31 & 25 \\
\hline & Informatics and Economics & 180 & 62 & 53 \\
\hline Master & Business Administration & 150 & 52 & 44 \\
\hline & Finance & 150 & 52 & 48 \\
\hline 1.b. Faculty of & latural Sciences & & & \\
\hline Master & Informatics & 60 & 21 & 18 \\
\hline 2. Polytechni & University of Tirana & & & \\
\hline 2.a. Faculty of & lectrical Engineering & & & \\
\hline Master & Electrical Engineering & 60 & 21 & 18 \\
\hline 3. Agricultura & University of Tirana & & & \\
\hline 3.a. Faculty of & latural Sciences & & & \\
\hline Bachelor & Agricultural Economy & 150 & 52 & 52 \\
\hline Master & Finance & 100 & 35 & 35 \\
\hline & Total & 1.730 & 600 & 556 \\
\hline
\end{tabular}

\subsection{Structural Equation Modeling (SEM)}

For a long time the Method of Least Squares (MLS) has dominated the stochastic methods in social research. These regressive models are widely used in various fields of research, such as economics, when trying to find a relationship between a dependent variable and one or more independent variables. An important feature of these regression models is the assumption of the single dependent variable as the only variable subject to measurement error or other random variations. The independent variables are assumed fixed and known values to the researcher. This assumption leads to a considerable limit, given that evidence shows much more complex scenarios where hardly the independent variables are not subject to measurement errors. Another limitation of traditional models of regression is the absence of latent variables, the causal relationships between variables and their interdependence (Jairo, 2008).

The structural equation models (SEM), unlike the conventional regression models do not represent these constraints, considering the complexity of the relationships between all the variables.

Through SEM we can determine the direct and indirect effects of individual charateristics, know how, attitude, perceived desirability, self-efficacy, subjective norms and feasibility on entrepreneurship intentions.

\subsection{Goodness of Fit}

The model resultsare shown in Table 4. The data were elaborated with AMOS and SPSS 22.0.

Structural equation model output results show that the overall model fits significantly, with chi-square $=3405.036$ and degree of freedom $=1369$ at a probability level of 0.000 ; results from absolute fit indicators, CFI, RMSEA and HOELTER were acceptable, indicating model fit is acceptable; from the relative fit indicator, CFI is between 0.9 and 1 , showing that the model fit well. $X 2 / \mathrm{df}$ is 2.487 , less than the maximum cutoff value of 3 ; RMSEA value of 0.058 is less than the maximum $0.08 ; \mathrm{CFI}=0.94$ is greater than the requirement of at least 0.9. All these indexes are consistent confirmingagood fit of the model (Table 2). 
Table 2. Goodness of Fit

\begin{tabular}{|cccccc|}
\hline $\mathbf{X} 2$ & df & X2/df & HOELTER & CFI & RMSEA \\
\hline 3,405 & 1,369 & 2.487 & 203 & 0.94 & 0.058 \\
\hline$p$-value $=0.000$ & Acceptable & Acceptable & Acceptable & Acceptable \\
\hline
\end{tabular}

Since most of the variables of the model, except for individual characteristics, are not observed, the latents were tested for internal consistency with the Cronbach's Alpha. The a values over .80 show a good internal consistency. Still, values in the range from .60 to .80 are still considered consistent (Cortina, 1993).

The latent variables show all a good internal consistency (Table 3). Some questions may be raised for the desirability construct, since it's a value is .71. Yet, it can be considered for further consistency within the model, since its consistency can still be reliable (Cortina, 1993).

Table 3: Internal Consistency, Cronbach'sa

\begin{tabular}{|lcc|}
\hline Latent Variable & N. of Questions & Cronbach's $\boldsymbol{\alpha}$ \\
\hline attitude & 9 & .82 \\
\hline desirability & 2 & .71 \\
\hline intention & 2 & .80 \\
\hline know_how & 16 & .86 \\
\hline self_efficacy & 13 & .80 \\
\hline feasibility & 5 & .79 \\
\hline
\end{tabular}

\section{Results}

The results are shown in Table 4, while the main relations are represented in Figure 2. The individual characteristics are fair determinants of the attitude. While Age is not significant, the rest of the characteristics show a positive relationship with attitude. Gender relation with Attitude shows that males have .308 more inclining intention towards entrepreneurship than women. The fact of having entrepreneurs as family members gives more attitude than having none (+.190), but this is lower than the gender relation. Experince is a determinant of attitude, despite the fact it is significant at the highest acceptable value ( $p$-value is quite .10) and with a lower effect than the other two determinants (.096).

On the other hand, Attitude shows to be a relevant determinant of entrepreneurship intention. It has a significant and strong direct relation to Intention (.737), confirming the first hypothesis. The indirect effect through Perceived Desirability is not significant (.086), despite the fact that it has a positive and significant relationship of .974 , which leads to a very strong relation.

Subjective norms, measured through family support in entrepreneurship initiatives, shows a weak but significant positive relationship with Intention. This confirms our second hypothesis.

The relationship between Know how and Self Efficacy shows as well a very strong and significant coefficent of .964 .

Self Efficacy has a non-significant direct relationship with Intention. Still, it has a indirect relationship with Intention, throught Feasibility. Since the relationship with Feasibility is significant at $p=.000$, and in addition, Feasibility has a direct significant relationship of .141, it can be concluded that there is an indirect relationship between Self Efficacy and Intention. This finding is also consistent with prior research that finds self-efficacy related to the perceptions of feasibility (Krueger et al. 2000). Thus, despite the non-significance of the direct effects, the third hypothesis is confirmed throgh the indirect effects. 


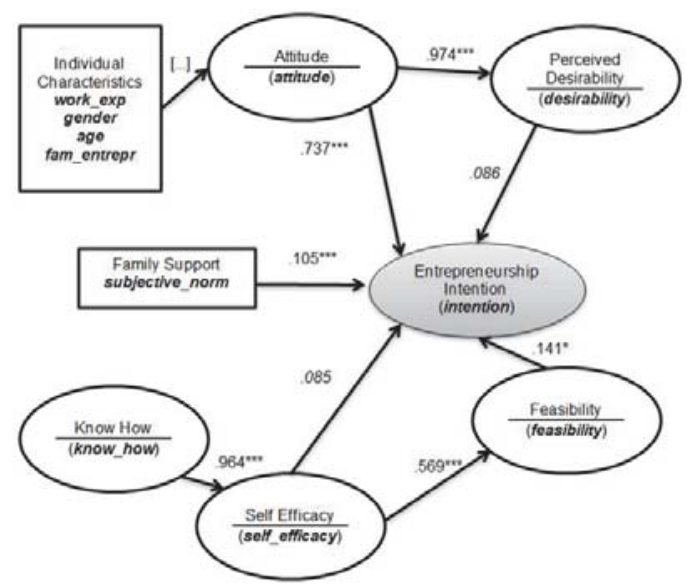

Figure 2: Model Estimation

\section{Conclusions}

This study is focused on the factors determining entrepreneurial intention of the albanian students. More specifically we have reviewed the determinants of entrepreneurial orientation of students by investigating the direct antecedent of planned behavior (Ajzen, 1991).

We investigate the relationship between attitude, social norm and self-efficacy with entrepreneurial intention. The results confirm the positive relationship between attitude and entrepreneurialintetion. Students attitude proves to be a good determinant of the entrepreneurship intention, confirming our first hypothesis.

In addition, we find a positive relationship between social norm and entrepreneurintetions. The perceived behavioral control or self-efficacy shows an indirect relation with entrepreneurial intention but non-significant for its direct effects. This is consistent with Krueger et al. (2000) findings, where the mediation effect accounts for most of the relationship.

The results show that social norms and entrepreneurial attitude are factors that influence and determine the entrepreneurial intetion. The relation between them is positive and statistically significant.

This study aims in understanding the factors that affect entrepreneurial intention and behavior. There are several limits that concern the study. First, the selection includes only public universities located in Tirana, while it could be useful to include universities in different regions and from the private sector as well. Second, a auto-selection issue might be considered as well, due to the fact that the questionnaires were distributed in hard copy during lectures, seminars or tests.Another issue to be considered is related to the years of study of the students, which is not considered into this model.

Further analysis that can be developed in this field may take into account the study of gender and study the connection between male and female students in entrepreneurial intention.

Table 4: Regression Weights

\begin{tabular}{|lllcccc|} 
& & & Estimate & S.E. & C.R. & P \\
\hline self_efficacy & $<---$ & know_how & .964 & .143 & 6.715 & $* * *$ \\
attitude & $<---$ & age & -.014 & .007 & -1.828 & .068 \\
attitude & $<---$ & gender & .308 & .072 & 4.246 & $* * *$ \\
attitude & $<---$ & fam_entrepr & .190 & .058 & 3.299 & $\star * *$ \\
attitude & $<---$ & work_exp & .096 & .058 & 1.648 & .099 \\
feasibility & $<---$ & self_efficacy & .569 & .086 & 6.581 & $* * *$ \\
desirability & $<---$ & attitude & .974 & .082 & 11.816 & $* * *$ \\
intention & $<---$ & desirability & .086 & .066 & 1.293 & .196 \\
intention & $<---$ & attitude & .737 & .095 & 7.770 & $* * *$ \\
\hline
\end{tabular}




\begin{tabular}{|c|c|c|c|c|c|c|}
\hline intention & $<--$ & subjective_norm & .105 & .045 & -2.802 & .003 \\
\hline intention & $<--$ & self_efficacy & .084 & .080 & 1.054 & .292 \\
\hline intention & $<--$ & feasibility & .141 & .079 & 1.773 & .076 \\
\hline skill_positive_vision & $<--$ & know_how & 1.000 & & & \\
\hline conv_your_vision & $<--$ & know_how & 1.022 & .140 & 7.318 & *** \\
\hline conv_vision_to_others & $<--$ & know_how & 1.052 & .137 & 7.677 & *** \\
\hline build_negoc & $<--$ & know_how & 1.106 & .150 & 7.360 & *** \\
\hline form_value & $<--$ & know_how & .952 & .141 & 6.775 & *** \\
\hline skill_to_creat_work_env & $<--$ & know_how & 1.032 & .142 & 7.289 & *** \\
\hline skill_to_encourage ${ }^{-}$ & $<--$ & know_how & 1.031 & .137 & 7.553 & *** \\
\hline skill_create_interact_working & $<--$ & know_how & 1.252 & .159 & 7.862 & *** \\
\hline skill_aleance & $<--$ & know_how & 1.201 & .156 & 7.722 & *** \\
\hline skill_identify_manager & $<--$ & know how & .915 & .129 & 7.084 & *** \\
\hline skill_recrut_train & $<--$ & know_how & 1.258 & .170 & 7.402 & *** \\
\hline skill_choose_manager & $<--$ & know_how & 1.066 & .146 & 7.278 & 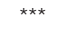 \\
\hline skill_measure_capacity & $<--$ & know_how & 1.105 & .154 & 7.169 & 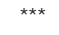 \\
\hline skill_identify_investor & $<--$ & know_how & .948 & .141 & 6.702 & *** \\
\hline skill_resources & $<--$ & know_how & 1.168 & .157 & 7.444 & $* \star *$ \\
\hline skill_develop_maintain_investors & $<--$ & know_how & 1.000 & .142 & 7.042 & *** \\
\hline skill_failure & $<--$ & self_efficacy & 1.000 & & & \\
\hline skil_continue & $<--$ & self_efficacy & .896 & .117 & 7.686 & $* * *$ \\
\hline skill_tolerate & $<--$ & self_efficacy & .693 & .118 & 5.882 & *** \\
\hline skill_stressful_conditions & $<--$ & self_efficacy & .880 & .124 & 7.094 & *** \\
\hline skill_changes & $<--$ & self_efficacy & 1.018 & .119 & 8.571 & $* \star *$ \\
\hline reach_to_quotas & $<---$ & self_efficacy & 1.193 & .121 & 9.890 & 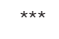 \\
\hline react_to_changes & $<--$ & self_efficacy & 1.257 & .126 & 10.004 & *** \\
\hline positioning_market & $<--$ & self_efficacy & 1.142 & .119 & 9.588 & *** \\
\hline improve_services & $<--$ & self_efficacy & .802 & .101 & 7.979 & $\star \star *$ \\
\hline improve_prod & $<--$ & self_efficacy & .656 & .093 & 7.017 & *** \\
\hline develop_new_prod & $<--$ & self_efficacy & .840 & .109 & 7.721 & $* \star *$ \\
\hline develop_new_ideas & $<--$ & self_efficacy & .831 & .106 & 7.857 & *** \\
\hline intention_to_success & $<--$ & self_efficacy & .893 & .111 & 8.041 & *** \\
\hline think_enterp & $<--$ & attitude & 1.000 & & & \\
\hline chief_own & $<--$ & attitude & .872 & .085 & 10.286 & *** \\
\hline think_enterp & $<--$ & attitude & .896 & .073 & 12.206 & 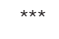 \\
\hline futurēenterp & $<--$ & attitude & .933 & .067 & 13.847 & *** \\
\hline opport_enterp2 & $<--$ & attitude & 1.108 & .076 & 14.492 & *** \\
\hline sadisfaction_entrep & $<--$ & attitude & .914 & .070 & 13.046 & $* * *$ \\
\hline opport_enterp & $<--$ & attitude & .850 & .065 & 13.146 & $* * *$ \\
\hline attractē__build_entrep & $<--$ & attitude & .762 & .088 & 8.678 & *** \\
\hline entrep_advantāge & $<--$ & attitude & .678 & .070 & 9.710 & *** \\
\hline know_details & $<--$ & feasibility & 1.000 & & & \\
\hline inspect_startup & $<--$ & feasibility & 1.350 & .145 & 9.294 & 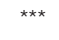 \\
\hline respons_entrep & $<--$ & feasibility & 1.632 & .168 & 9.723 & $* * *$ \\
\hline easy_entrep & $<--$ & feasibility & 1.344 & .143 & 9.378 & *** \\
\hline create_project & $<--$ & feasibility & .865 & .122 & 7.104 & $\star \star \star *$ \\
\hline source_colleagues & $<--$ & subjective2 & 1.000 & & & \\
\hline source_friends & $<--$ & subjective2 & .790 & .227 & 3.474 & *** \\
\hline entrep_intent & $<--$ & desirability & 1.000 & & & \\
\hline ready_entrep & $<--$ & desirability & .895 & .077 & 11.651 & $\star \star \star *$ \\
\hline interest to star & $<--$ & intention & 1.000 & & & \\
\hline interest_entrep & $<--$ & intention & .968 & .067 & 14.446 & 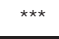 \\
\hline
\end{tabular}

\section{References}

Ajzen, I. (1987). Attitudes, traits, and actions: Dispositional prediction of behavior in social psychology.Advances in Experimental Social Psychology, 20, 1-63.

Ajzen, I. (1991). The theory of planned behavior. Organizational Behavior and Human DecisionProcesses, 50, 179-211.

Ajzen, I. (2005). Attitudes, Personality and Behavior. Maidenhead, England; New York: Open University Press,.

Autio, E., Keeley, R. H., Klofsten, M., Parker, G. G. C., \& Hay, M. (2001). Entrepreneurial intent amongstudents in Scandinavia and in 
the USA. Enterprise and Innovation Management Studies, 2, 145-160.

Cortina, J.M. (1993). "What is coefficient alpha? An examination of theory and applications". Journal of Applied Psychology. 78: 98-104

Fishbein, M., Ajzen, I. (1975). Belief, attitude, intention, and behavior: An introduction to theory andresearch. Reading, MA: AddisonWesley.

Jairo, I. (2008). The use of Structural Equation Modelling (SEM) in Capital Structure Empirical Analysis. Journal of Business Management, 1 (1), 11-35.

Johnson, D., Craig, J. B., \& Hildebrand, R. (2006). Entrepreneurship education: towards a discipline-based framework. Journal of Management development, 25(1), 40-54.

Kirzner, I. M. (1997). How markets work: Disequilibrium, entrepreneurship and discovery (No. 133). Coronet Books Incorporated.

Kolvereid, L. (1996). Prediction of employment status choice intentions. Entrepreneurship Theory and Practice, 21, 47-57.

Kolvereid, L., Isaksen, E. (2006). New Business Start-up and Subsequent Entry into Selfemployment.Journal of Business Venturing , 21 (6), 866-885.

Krueger, N. (1993). The impact of prior entrepreneurial exposure on perceptions of new venture feasibilityand desirability. Entrepreneurship: Theory and Practice, 18(1), 5-21.

Krueger Jr., N. F., Reilly, M. D., Carsrud, A. L. (2000). Competing models of entrepreneurial intentions.Journal of Business Venturing, 15, 411-432.

Tkachev, A., Kolvereid, L. (1999). Self-employment Intentions among Russian Students. Entrepreneurship and Regional Development , 11, 269-280.

Shapero, A., Sokol, L. (1982). The social dimensions of entrepreneurship. Encyclopedia of entrepreneurship, 72-90.

Sheppard, B. H., Hartwick, J., \& Warshaw, P. R. (1988). The theory of reasoned action: A meta-analysis of past research with recommendations for modifications and future research. Journal of consumer research, 325-343. 
